\title{
Sensitivity of the dispatch strategy in designing grid integrated hybrid energy systems
}

\author{
A.T.D. Pereraa, Dasaraden Maureea, Jean-Louis \\ Scartezzini \\ Solar Energy and Building Physics Laboratory (LESO- \\ PB), Ecole Polytechnique Fédérale de Lausanne (EPFL), \\ CH-1015 Lausanne, Switzerland
}

\begin{abstract}
Integrating renewable energy technologies based on solar PV (SPV) and wind energy in the energy system is challenging due to time dependence of the energy potential for these energy sources. Grid integrated hybrid energy systems combining SPV panels, wind turbines, battery bank and internal combustion generators (ICG) can be used in this regard specially for distributed generation. Energy-economic dispatch strategy plays a vital role in managing the energy flow of the system. However, it is difficult to design such energy system due to complexity of the energy flow because of the changes in electricity demand, solar and wind energy potential.

This study evaluates the sensitivity of dispatch strategy on optimum system configuration considering Levelized Energy Cost (LEC) and Grid Integration Level (GI). Two existing dispatch strategies i.e. cycle charging (CC) and modified cycle charging (MCC) dispatch strategies are used for the analysis based on Pareto multi objective optimization of LEC and GI. Pareto-fronts obtained considering both approaches were subsequently compared for different grid curtailments. The results show that a notable difference in LEC and system configuration is observed for two different approaches with the increase of grid interactions.
\end{abstract}

Index Terms-- Distributed Generation, energy-economic dispatch, renewable energy integration, multi-objective optimization.

\section{INTRODUCTION}

There is a worldwide growth in optimum design of energy systems and integration of renewable energy technologies, which makes the penetration level of solar PV (SPV) and wind energy notably high [1]. However, the stochastic nature of solar and wind energy sources makes it difficult to supply the demand continuously. Fluctuating potentials of the solar and wind energy necessitate amalgamating energy storage and dispatchable energy sources for maintaining the system reliability [2]-[4]. Combining dispatchable energy sources and energy storage helps to increase the utilization of renewable energy while minimizing energy losses due to grid curtailments, though energy systems with and/or without dispatchable energy sources and energy storage formulate complex energy flows

\author{
Vahid M. Nik \\ Division of Building Physics, Department of Building and \\ Environmental Technology, Lund University, Lund, Sweden
}

[5]. The optimum design of such integrated energy systems has been studied and different approaches are used to present the dispatch strategy in designing system configuration [6], [7].

A number of recent studies have focused on developing optimization techniques to design distributed energy systems. When considering the grid integrated energy systems, different methods have been used to consider the influence of dispatch strategy into the energy system design. The basic method used in this regard is simulating the grid integrated energy systems with the use of a simple dispatch strategy and formulating objective functions. These objective functions are subsequently used to optimize the system configuration. Furthermore, this has been extended considering more detailed states of operation where finite state theory is used to consider the operating condition of the system [8]-[11]. Both direct search [12], [13] and heuristic methods [9], [11], [14] are used to optimize these systems. In addition, dynamic optimization is used to optimize the operating condition of the system which is subsequently applied for determining the system configuration [15], [16]. However, selected day hour method is used in most of these instances in order to bring the computational time into a reasonable period [16]. Considering all the aforementioned techniques, different operating methods have been used for determining the optimum system design. However, a comparison of these techniques is missing in the literature.

This study performs the sensitivity analysis of the dispatch strategy used for optimizing the system configuration on the Levelized Energy Cost (LEC) and system configuration. Two different dispatch strategies are used to design grid integrated hybrid energy systems. The first method is based on simple cycle charging method (CC) and the second method is a modified cycle charging strategy where energy flow from energy storage is managed considering the real time price of the grid. A concise description about the computational model used to consider the energy flow and cash is presented in Section 3. Section 4 presents a detailed description about the two adopted dispatch strategies. Section 5 presents the 
optimization algorithm used to optimize the systems considering LEC and Grid Interaction (GI) as objective functions. Finally, Section 6 presents a detailed discussion of results to evaluate the sensitivity of dispatch strategy on optimum system configuration for different grid integration level.

\section{OVERVIEW OF THE ENERGY SYSTEM}

The studied grid-integrated hybrid energy system consists of SPV panels and wind turbines which can be classified as non-dispatchable energy sources. An Internal Combustion Generator (ICG) is connected to the energy system which works as a dispatchable energy source while a battery bank is used as the energy storage. The energy/electricity grid is maintaining energy interactions with the utility grid of the Energy Service Provider (ESP) within curtailments. In addition, price of electricity is assumed to vary on hourly basis. An overview of the system is presented in Figure 1.

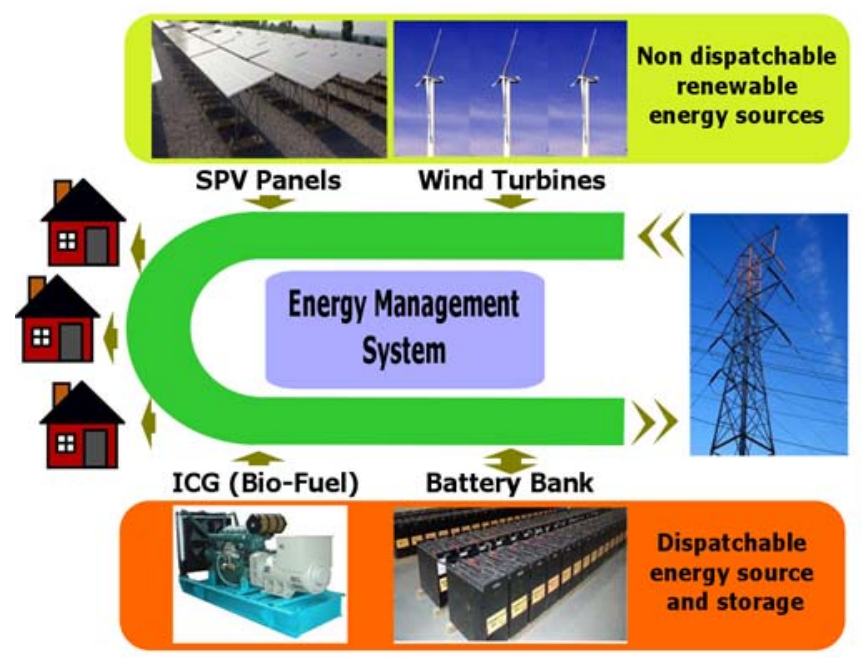

Figure 1 overview of the energy flow of the energy system

\section{ENERGY-ECONOMIC MODEL}

An energy-economic model is used in this study to formulate the energy flow through each component on hourly basis. Lifecycle cost of the system is calculated considering all the cash flows that take place in different periods of time. Time series data for wind speed, solar irradiation, and ambient temperature are taken from meteorological records. Power generation of the non-dispatchable energy sources and operation of the dispatchable energy sources are determined using the dispatch strategy which is elaborated in detail in section 4.

The energy balance of the system is maintained through power generated using SPV panels, wind turbines, ICG and interactions with the battery bank and the main utility grid. Power generation from non-dispatchable energy sources depends on the installation capacity of SPV panels and wind turbines as well as the energy potential of the considered location, which varies with respect to time.
Hourly horizontal global solar irradiation data are taken in this study to determine the power generated from SPV panels. An isotropic model is used to calculate the solar irradiation on tiled surface. Durisch model is used to calculate the electricity generation of SPV panels [17]. Finally, net energy generation of SPV panels, $\mathrm{P}_{\mathrm{SPV}}(\mathrm{t})$, is calculated on hourly basis using Eq. 1.

$P_{S P V}(t)=G_{\beta} \eta_{p v} A_{S P V} N_{S P V} \eta_{\text {spv-inv }}$

where $\eta_{\text {spv-inv }}$ denotes the efficiency of the inverter, $\mathrm{N}_{\mathrm{SPV}}$ denotes the number of SPV panels which is optimized using the optimization algorithm, $\mathrm{A}_{\mathrm{SPV}}$ denotes collector area and $\mathrm{G}_{\beta}$ denotes global horizontal solar irradiation on the tilted SPV panel. $\eta_{\mathrm{pv}}$ denotes the efficiency of SPV panel.

Similarly, hourly wind speed at $10 \mathrm{~m}$ anemometer height is taken for the same location. Cubic spline interpolation technique [18] is used to model the wind turbine based on the power curve provided by the manufacturer. Finally, electric power from the wind turbines is calculated according to Eq. 2.

$\mathrm{P}_{\mathrm{w}}(\mathrm{t})=\breve{\mathrm{P}}_{\mathrm{w}}(\mathrm{t}) \mathrm{N}_{\mathrm{w}} \eta_{\mathrm{w}-\mathrm{inv}}$

where $\mathrm{N}_{\mathrm{w}}$ denotes number of wind turbines which is optimized in the optimization algorithm and $\eta_{\mathrm{w} \text {-inv }}$ denotes inverter efficiency. $\breve{\mathrm{P}}_{\mathrm{w}}$ is calculated based on wind speed of the respective hour and wind turbine power curve. Operating load factor of the ICG is determined by the dispatch strategy and used to determine the fuel consumption of the ICG. Finally the capacity of the ICG is optimized using the optimization algorithm. State of Charge (SOC) model is used to compute the charge level of the battery bank while Rain Flow Algorithm based on Downing's Algorithm [19] is selected to compute the lifetime of the battery bank. . Load mismatch indicator introduced by Salom et al [20] to evaluate effectiveness of net-zero energy buildings is used in this study as the performance indicator for system autonomy defined as grid integration level according to Eq. 3 .

$\mathrm{GI}_{\mathrm{FG}}=\sum_{t=1}^{t=8760} P_{F G}(t) / \sum_{t=1}^{t=8760} P_{E L D}(t)$

In these equations $\mathrm{P}_{\mathrm{ELD}}(\mathrm{t})$ denotes the hourly ELD and $P_{F G}(t)$ denote energy units taken from the grid with in a time step.

A detailed description about the energy model used can be found in Ref.[11], [21], [22].

The cost model, used for this study, evaluates the initial capital cost for the system components, operation and maintenance cost $(\mathrm{OM})$ of the system. Initial capital cost of the system considers both acquisition cost of the system components and installation costs. Cash flows related to operation and maintenance of system devices are considered in OM. Regular maintenance cost for wind turbines, SPV panels and ICG are considered along with replacement cost for ICG and battery bank. In addition, net cash flow of the system while interacting with the main utility grid is 
considered under OM. Real time Cost of Energy (COE) is used in this work for both selling and purchasing. Finally, the Levelized Energy Cost (LEC) is calculated considering all the cash flows. LEC is taken as an objective function to be optimized.

\section{DisPatCH STRATEGIES USED}

A number of dispatch strategies have been introduced in recent studies. These are combined later with optimization algorithm for simultaneous optimization of system design and dispatch strategy [12]. The modified cycle charging (MCC) strategy [8], [21], [23] and Cycle Charging (CC) strategy are the two methods compared in this study[6].

CC strategy is amply used in micro-grid design tools, mainly due to its simplicity which minimize the dimensions of decision space for design optimization. CC operates in four main states as shown in Figure 2 depending on condition of ICG and the difference between renewable generation (RE) and the Electricity Load Demand (ELD). These four states are battery charging, battery discharging, injecting excess generated which cannot be stored in battery bank and working as a load point to the grid. When power generation using renewable energy is not sufficient enough to provide the demand ICG is operated at full load. Excess power generated is directed to the battery bank which is the first operating state. Whenever, battery bank is at its maximum state of charge excess power generated is directed to the grid. Power generated using both dispatchable and nondispatchable energy sources are not sufficient enough to cater the load mismatch (PA) system interacts with the battery bank. Whenever, battery bank cannot provide the mismatch main utility grid is considered. All these interactions take place considering grid curtailments for injecting $\left(\mathrm{TG}_{\mathrm{lim}}\right)$, as a load point $\left(\mathrm{FG}_{\mathrm{lim}}\right)$ and State of Charge (SOC) of the battery bank.

Major weakness in $\mathrm{CC}$ is that it does not consider number of possible operating states. For example, it is possible to charge battery bank using grid electricity when COE in utility grid is quite cheap and discharge battery bank to sell electricity when it is quite expensive in utility grid. In addition, CC directly moves into battery bank whenever there is a mismatch in providing demand or excess generation where MCC consider the COE in main utility grid and decide whether to move into battery bank or grid. MCC considers these options through an extended state space which increase the possible main operating states up to eight as shown in Figure 3. In addition, the rules for state transition need to be trained along with system optimization which extends the decision space for the optimization algorithm in this method. However, dispatch algorithm for MCC is not presented in this paper to make the discussion simple. For a detail description about the dispatch strategy authors recommend to go through Ref. [8], [21], [23].

\section{OPTIMIZATION ALgORITHMS}

Reaching to the optimum configuration of the system is possible through using the optimization algorithm. The first part in the algorithm is deriving optimum capacity for wind turbines, SPV panels, battery bank and ICG considering the particular application. In addition, type of wind turbines and SPV panels need to be determined. LEC and GI are taken as objective functions to be minimized in this study. The mathematical model which was introduced in Section 3 is used to formulate the objective functions.

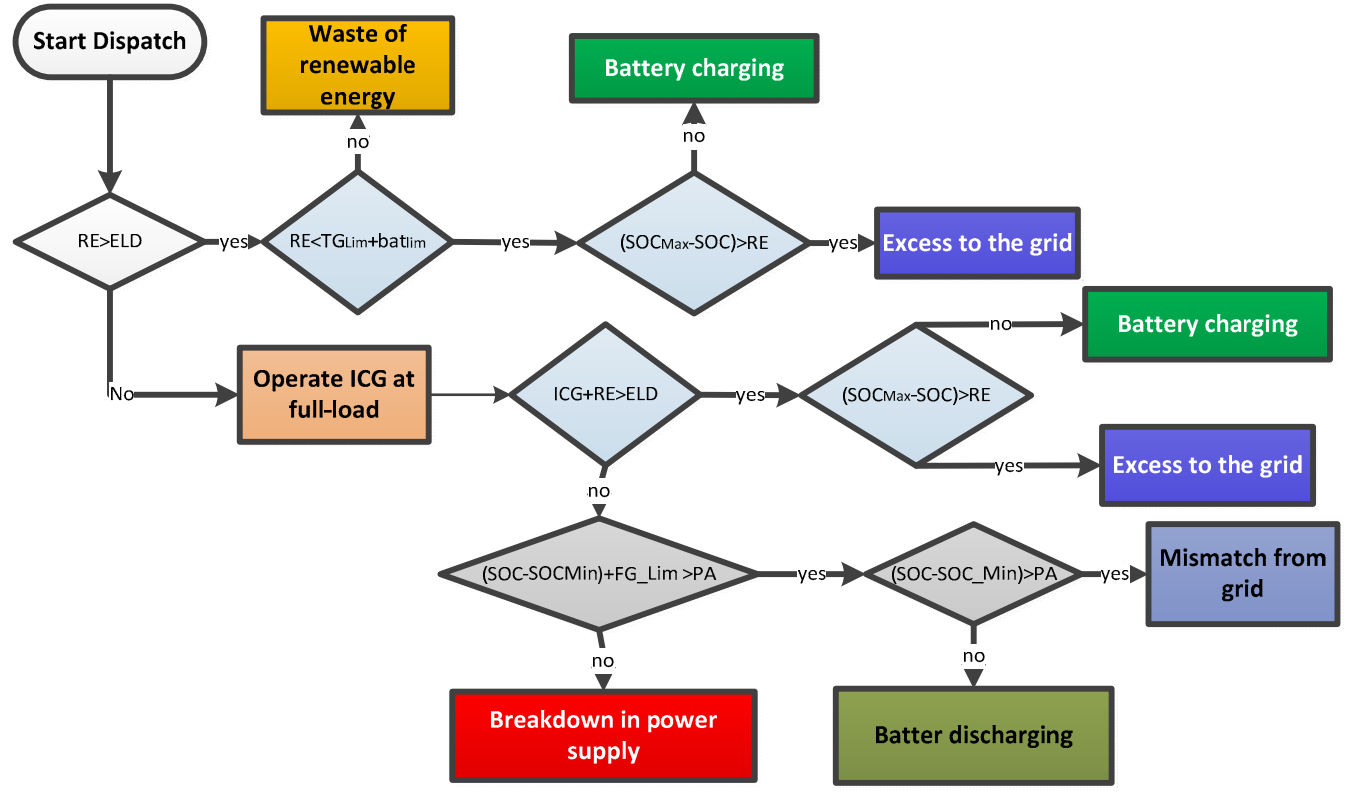

Figure 2 Overview of Cycle Charging strategy 


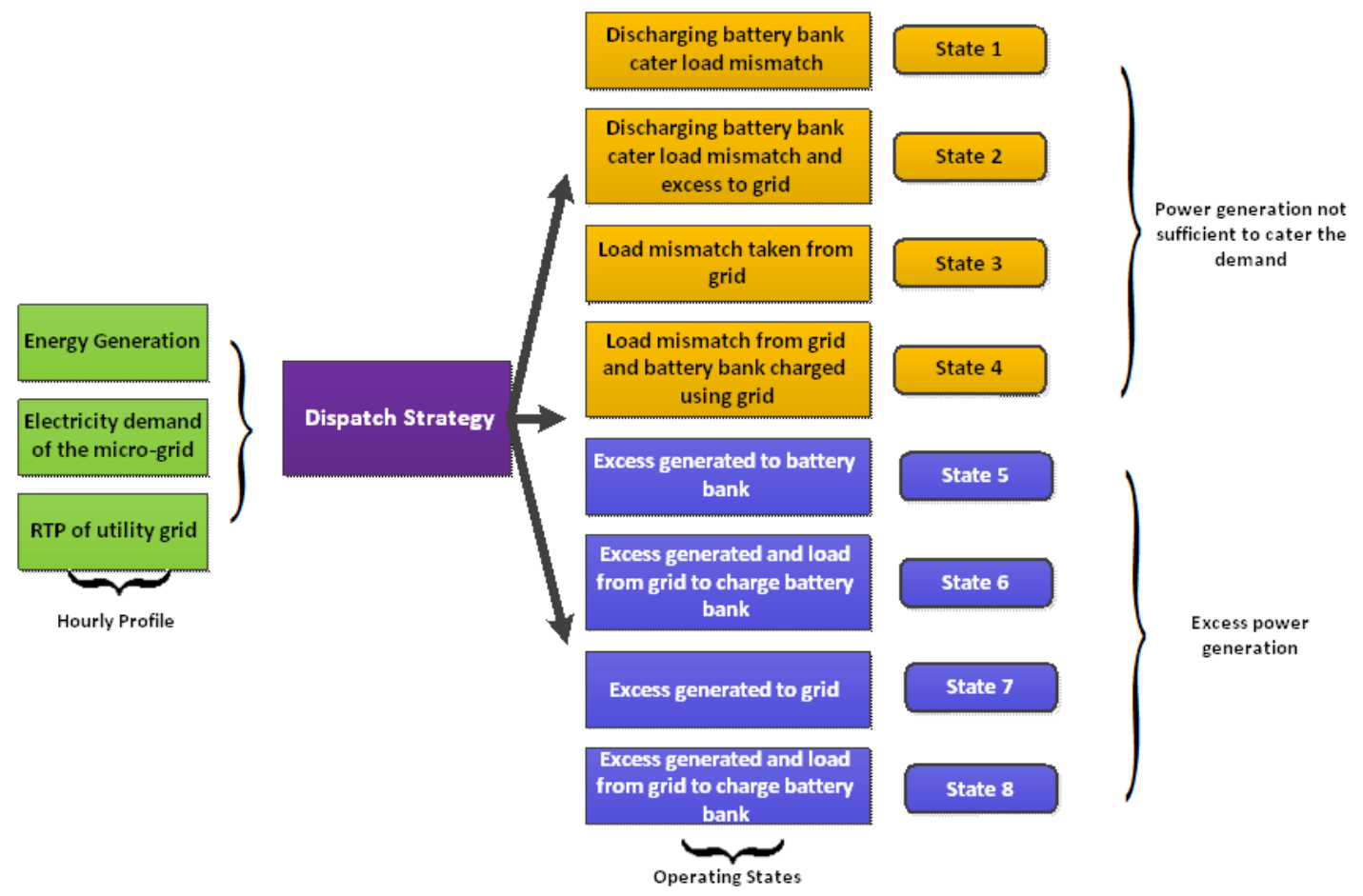

Figure 3 Schematic presentation of Modified Cycle Charging strategy

The two approaches in Section 4 are used as the dispatch strategy when simulating the system in the optimization algorithm. Time series simulation of the system makes objective space to be neither linear nor analytical, especially due to the non-linearity in the performance curves of the system devices. Therefore, a heuristic multi objective optimization method based on Steady $\varepsilon$-State Evolutionary Algorithm is used in this study to come up with Pareto fronts. An illustrated explanation about the optimization algorithm and declaration of the decision space variables can be found in Ref. [14].

\section{RESULTS AND DISCUSSION}

Classical cost optimization cannot be used to evaluate the effectiveness of the dispatch strategy due to several reasons. Cost optimization results in one solution which is the main limitation. Furthermore, there are limitations in representing the energy interactions through an objective function based on cost. Hence, multiple objectives considering technoeconomical aspects are required to evaluate effectiveness of the optimization algorithm. The LEC and GI are two parameters which can be used to evaluate the performance of the system considering both cash and energy flow. The Pareto fronts, obtained using multi objective optimization, are used in this study to evaluate the sensitivity of two dispatch strategies.

Three Pareto fronts are obtained considering grid curtailments of $100 \%, 90 \%$, and $80 \%$ (Case A, Case B and Case C) of peak demands for both methods. Pareto fronts obtained using both methods for each curtailment are presented in Figure 4 . When analyzing all the Pareto fronts a notable reduction in LEC is observed for all the Pareto fronts with the introduction of strong interactions with main utility grid. However, gradient of the Pareto front gradually get reduce with the increase of grid interactions. When considering the sensitivity of dispatch strategy, both these strategies does not show a significant difference when reaching GI levels less than $2 \%$. In such instances, system tends to behave as a standalone system where the both dispatch strategies tend to react in a similar way. Subsequently with the improvements in grid interactions, MCC shows a reduction in LEC when compared to $\mathrm{CC}$. MCC is having an extended state space which helps the system to interact with the grid and energy storage effectively. However, grid interaction plays a major role on this regard.

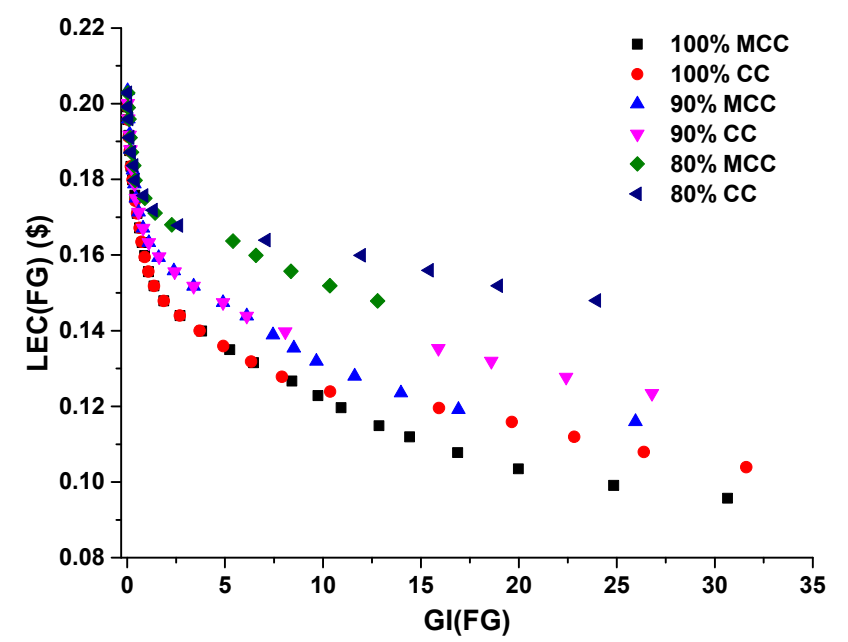

Figure 4 LEC-GI Pareto front considering grid curtailments of 100\%, 90\% and $80 \%$ of peak demand 
Notable changes in LEC make it interesting to analyze the influence of dispatch strategy further. First, the influence of the dispatch strategy on system design is considered which is continued considering utilization of renewable energy subsequently. In order to assess the influence of dispatch strategy on system design, renewable energy capacity of the system for Pareto solutions is plotted for Case A in Figure 5. When analyzing the results it is clear that notable increase in renewable energy capacity is observed for MCC when GI is higher than $10 \%$ which corresponds to the LEC graph which shows a clear difference in LEC. When analyzing the utilization of renewable energy for both operating strategies, it is noted that waste of renewable energy due to storage limitation is quite less in MCC when compared to $\mathrm{CC}$ even with higher level of renewable energy integration. Main reason for this is energy systems which use MCC as the dispatch strategy interacts with utility grid more effectively when considering both energy flows coming to the energy system and going out.

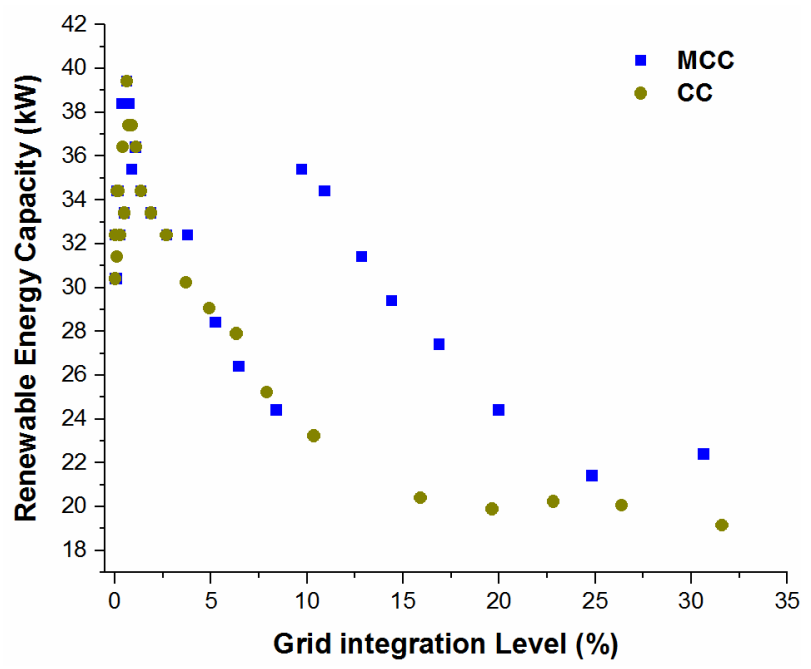

Figure 5 Variation of renewable energy capacity for Case A

\section{CONCLUSIONS}

This study highlights the importance of analyzing the sensitivity of dispatch strategy when designing grid integrated hybrid energy systems. Two different operation strategies were considered in this study using Pareto optimization. The results obtained from the Pareto analysis depict that MCC is helpful to reach lower LECs when compared to CC. Extension of state space helps to interact with the main utility grid more effectively which helps to integrate more renewable energy with higher utilization. More importantly, Energy system configuration obtained using two different approaches show significant changes, especially with the increase of grid integration level. Hence it is important to select proper dispatch strategy when designing grid integrated energy systems.

\section{REFERENCES}

[1] S. Sinha and S. S. Chandel, "Review of recent trends in optimization techniques for solar photovoltaic-wind based hybrid energy systems," Renew. Sustain. Energy Rev., vol. 50, pp. 755-769, Oct. 2015.

[2] M. Yekini Suberu, M. Wazir Mustafa, and N. Bashir, "Energy storage systems for renewable energy power sector integration and mitigation of intermittency," Renew. Sustain. Energy Rev., vol. 35, pp. 499-514, Jul. 2014.

[3] M. L. Kubik, P. J. Coker, and C. Hunt, "The role of conventional generation in managing variability," Energy Policy, vol. 50, pp. 253 261, Nov. 2012.

[4] A. T. D. Perera, R. A. Attalage, and K. K. C. K. Perera, "Optimal design of a grid connected hybrid electrical energy system using evolutionary computation," in 2013 8th IEEE International Conference on Industrial and Information Systems (ICIIS), 2013, pp. $12-17$.

[5] A. T. D. Perera, D. M. I. J. Wickremasinghe, D. V. S. Mahindarathna, R. A. Attalage, K. K. C. K. Perera, and E. M. Bartholameuz, "Sensitivity of internal combustion generator capacity in standalone hybrid energy systems," Energy, vol. 39, no. 1, pp. 403-411, Mar. 2012.

[6] A. Mohammed, J. Pasupuleti, T. Khatib, and W. Elmenreich, "A review of process and operational system control of hybrid photovoltaic/diesel generator systems," Renew. Sustain. Energy Rev., vol. 44, pp. 436-446, Apr. 2015.

[7] X. Wang, A. Palazoglu, and N. H. El-Farra, "Operational optimization and demand response of hybrid renewable energy systems," Appl. Energy, vol. 143, pp. 324-335, Apr. 2015.

[8] R. Dufo-López and J. L. Bernal-Agustín, "Multi-objective design of PV-wind-diesel-hydrogen-battery systems," Renew. Energy, vol. 33, no. 12, pp. 2559-2572, Dec. 2008.

[9] R. Dufo-López, J. L. Bernal-Agustín, J. M. Yusta-Loyo, J. A. Domínguez-Navarro, I. J. Ramírez-Rosado, J. Lujano, and I. Aso, "Multi-objective optimization minimizing cost and life cycle emissions of stand-alone PV-wind-diesel systems with batteries storage," Appl. Energy, vol. 88, no. 11, pp. 4033-4041, Nov. 2011

[10] A. T. D. Perera, R. A. Attalage, K. K. C. K. Perera, and V. P. C. Dassanayake, "A hybrid tool to combine multi-objective optimization and multi-criterion decision making in designing standalone hybrid energy systems," Appl. Energy, vol. 107, pp. 412-425, Jul. 2013.

[11] A. T. D. Perera, R. A. Attalage, K. K. C. K. Perera, and V. P. C. Dassanayake, "Designing standalone hybrid energy systems minimizing initial investment, life cycle cost and pollutant emission," Energy, vol. 54, pp. 220-230, Jun. 2013.

[12] M. R. Basir Khan, R. Jidin, J. Pasupuleti, and S. A. Shaaya, "Optimal combination of solar, wind, micro-hydro and diesel systems based on actual seasonal load profiles for a resort island in the South China Sea," Energy, vol. 82, pp. 80-97, Mar. 2015.

[13] F. Fazelpour, N. Soltani, and M. A. Rosen, "Feasibility of satisfying electrical energy needs with hybrid systems for a medium-size hotel on Kish Island, Iran,” Energy, vol. 73, pp. 856-865, Aug. 2014.

[14] A. T. D. Perera, R. A. Attalage, K. K. C. K. Perera, and V. P. C. Dassanayake, "Converting existing Internal Combustion Generator (ICG) systems into HESs in standalone applications," Energy Convers. Manag., vol. 74, pp. 237-248, Oct. 2013.

[15] S. Jayasekara, S. K. Halgamuge, R. A. Attalage, and R. Rajarathne, "Optimum sizing and tracking of combined cooling heating and power systems for bulk energy consumers," Appl. Energy, vol. 118, pp. 124-134, Apr. 2014.

[16] S. Fazlollahi, P. Mandel, G. Becker, and F. Maréchal, "Methods for multi-objective investment and operating optimization of complex energy systems," Energy, vol. 45, no. 1, pp. 12-22, Sep. 2012.

[17] W. Durisch, B. Bitnar, J.-C. Mayor, H. Kiess, K. Lam, and J. Close, "Efficiency model for photovoltaic modules and demonstration of its application to energy yield estimation," Sol. Energy Mater. Sol. Cells, vol. 91, no. 1, pp. 79-84, Jan. 2007.

[18] S. Diaf, D. Diaf, M. Belhamel, M. Haddadi, and A. Louche, "A methodology for optimal sizing of autonomous hybrid PV/wind system," Energy Policy, vol. 35, no. 11, pp. 5708-5718, Nov. 2007. 
[19] S. D. Downing and D. F. Socie, "Simple rainflow counting algorithms," Int. J. Fatigue, vol. 4, no. 1, pp. 31-40, Jan. 1982.

[20] J. Salom, A. J. Marszal, J. Widén, J. Candanedo, and K. B. Lindberg, "Analysis of load match and grid interaction indicators in net zero energy buildings with simulated and monitored data," Appl. Energy, vol. 136, pp. 119-131, Dec. 2014.

[21] A. T. D. Perera, A. N. Madusanka, R. A. Attalage, and K. K. C. K. Perera, "A multi criterion analysis for renewable energy integration process of a standalone hybrid energy system with internal combustion generator," J. Renew. Sustain. Energy, vol. 7, no. 4, p. 043128, Jul. 2015.
[22] A. T. D. Perera, D. M. I. J. Wickremasinghe, D. V. S. Mahindarathna, R. A. Attalage, K. K. C. K. Perera, and E. M. Bartholameuz, "Determining wind turbine capacity for expansion of off grid Internal Combustion Generators (ICG) system; why it bec o mes challenging?," in 2010 IEEE International Conference on Sustainable Energy Technologies (ICSET), 2010, pp. 1-5.

[23] R. Dufo-López, "Optimisation of size and control of grid-connected storage under real time electricity pricing conditions," Appl. Energy, vol. 140 , pp. 395-408, Feb. 2015 